\title{
Association between mobile phone use and inattention in 7102 Chinese adolescents: a population-based cross-sectional study
}

Feizhou Zheng ${ }^{1}$, Peng Gao ${ }^{1}$, Mindi He ${ }^{1}$, Min Li ${ }^{1}$, Changxi Wang ${ }^{2}$, Qichang Zeng ${ }^{3}$, Zhou Zhou ${ }^{1}$, Zhengping Yu ${ }^{1}$ and Lei Zhang ${ }^{1 *}$

\begin{abstract}
Background: The dramatic growth of mobile phone (MP) use among young people has increased interest in its possible health hazards in this age group. The aim of this cross-sectional study was to investigate the association between MP use and inattention in adolescents.

Methods: A total of 7720 middle school students were involved in this cross-sectional study. Inattention was assessed as defined for the Attention Deficit component of Attention deficit/Hyperactivity disorder (ADHD) by the Diagnostic and Statistical Manual of Mental Disorders (4th ed., text rev. [DSM-IV-TR]). The demographic characteristics and information on MP use were included in the questionnaire. Chi-square tests and logistic regression models were used to analyze the data.

Results: In total, 7102 (91.99\%) valid questionnaires were obtained. After adjusted for confounders, inattention in adolescents was significantly associated with MP ownership, the time spent on entertainment on MP per day, the position of the MP during the day and the mode of the MP at night. The strongest association between inattention and the time spent on the MP was among students who spent more than 60 minutes per day playing on their MP.

Conclusions: Our study shows some associations between MP use and inattention in Chinese adolescents. Decreasing MP usage to less than 60 minutes per day may help adolescents to stay focused and centered.
\end{abstract}

Keywords: Mobile phone, Inattention, Chinese adolescents, Cross-sectional study

\section{Background}

With the incorporation of modern electronic products into daily life, adolescents now have a longer lifetime exposure to mobile phone (MP). China has developed into one of the world's largest MP markets. As today's adolescents frequently use MP and other communication tools in their homes, community environments and at school [1], they have longer exposure time to MP. In 2014, the proportion of adolescents who own MP is more than $60 \%$ in Shanghai, China [2] and still increasing. Additionally, with the increasing use of MP, concerns have been raised in a number of countries about the adverse

\footnotetext{
* Correspondence: zlepo1980@163.com

'Department of Occupational Health, Key Laboratory of Medical Protection for Electromagnetic Radiation, Ministry of Education, Third Military Medical University, NO. 30 Gaotanyan Street, Chongqing 400038, People's Republic of China

Full list of author information is available at the end of the article
}

health effects of MP use on adolescents. World Health Organization (WHO) has identified studies on the potential health effects of MP in children and adolescents as a high priority research area in their research agenda for radiofrequency fields [3].

Making calls, sending messages, surfing the internet and playing games on MP are very common in adolescents' lives, as is the wide use of smart phones. By the end of 2013, there were a total of 500 million people using MP to browse the internet in China [4]. It is unclear if MP use has adverse physiological and psychological effects on the development of adolescents. Inattention is one of the most prevalent mental health disorders in adolescents [5]. Inattentive symptoms, in particular, were strongly associated with problematic video game use or overuse also with other media [6]. These popularly operated MP games, often in brief segments, are not attention 
demanding and offer immediate rewards, which may encourage further playing [7]. Exposure to MP radio frequency electromagnetic fields might affect nonspecific neurologic performance such as attention and cognition [8]. Additionally, children absorb more energy from external electromagnetic fields than adults [9]. A growing number of studies have focused on the harmful effects of exposure to MP; however, only a few have investigated the association between inattention in adolescents and MP use.

MP has been found to be associated with inattention in a few studies $[10,11]$. One explanation of this association could be that the head is more exposed to electromagnetic radiation from MP rather than any other part of the body. Alternatively, subjects suffering from insomnia [12] or headaches [13] were found to have more inattention and many studies have reported that insomnia $[14,15]$ or headaches [16,17] occur more frequently with increasing exposure to MP. Furthermore, adolescents with inattention are at a higher risk of other psychiatric illnesses such as mood and conduct disorders, and substance abuse [18,19]. However, in a study using a MP exposure device, no difference in attention was observed between the sham and MP exposure groups [20,21]. Attention functions may also be differentially enhanced after exposure to the electromagnetic field emitted by MP [22-24].

Although there have been several studies on the association between MP use and attention, the results were still controversial. Our present study investigated the possible association between MP use and inattention in Chinese adolescents using a cross-sectional design.

\section{Methods}

\section{Ethics statement}

The protocol of this study was approved by the Third Military Medical University Ethical Committee. All study participants obtained written consent from their parents or guardians.

\section{Subjects}

In this cross-sectional survey, questionnaires were sent out to 7720 currently enrolled students from 4 middle schools in southwestern China. After obtaining written consent from the students' parents or guardians, the questionnaires were distributed and collected during school hours by the research staff who had previously received epidemiological survey training. The students could ask the research staff if they had any problems with the questions while they filled out the survey in the presence of their class teacher. Among the 7426 (96.19\%) students who responded to the questionnaire, $7102(91.99 \%)$ valid questionnaires were analyzed after excluding those with incomplete information.

\section{Questionnaire}

The questionnaire used in our research was designed to capture information about demographics, MP use, and inattention.

\section{Demographic information}

In the section on demographic information, name, sex (male or female), age, school, grade (7-12), and address (urban/rural) were listed.

\section{Information on MP use}

To obtain information about the time spent using a MP, students were asked to answer the following questions: "Do you own a MP?", "At what age did you start using a MP?", "How much time do you spend making phone calls per day?", and "How much time do you spend on MP entertainment (playing games and browsing the internet) per day?". MP usage was assessed using these questions: "How do you answer the phone (hold it close to your ear, hands-free, or use headphones)?"; "Where do you put your MP during the day (not carrying, hanging in front of the chest, in coat pockets, in trouser pockets, or in bags)?"; and "What is the mode of your MP at night (powered on and beside your head, powered on and kept away from your head, or powered off)?”. For all the above questions, MP use included using other people's phones. The question "Is there a mobile base station around your home or school?" was asked as well. Additionally, their answers would be checked with the information about the address of mobile base station provided by the Telco Providers and the consistent answers were used for analysis.

\section{Inattention}

Inattention was described as a lack of attention or a reduced attention span. Some examples of inattention include: avoiding school projects (which involve a long periods of concentration); losing school supplies; difficulties completing household chores; easily distractible et al. The prevalence of inattention in our study was screened using the most stable psychometric properties of the Attention Deficit component of Attention deficit/Hyperactivity disorder (ADHD) by the Diagnostic and Statistical Manual of Mental Disorders (4th ed., text rev. [DSM-IV-TR]) [25-27]. "A" criteria were used by the teachers who had previously received epidemiological survey training. The choice of nine inattention descriptions was "yes/no". Inattention was defined when the teacher chose six or more "yes" responses to the descriptions.

\section{Statistical analysis}

Chi-squared tests $\left(\chi^{2}\right)$ were used to compare the prevalence of inattention between different classifications of MP usage. Odds ratios (OR) and 95\% confidence intervals 
(95\% CI) were obtained using logistic regression models to assess the possible associations between MP ownership, years of MP usage, minutes spent on calls each day, minutes spent on entertainment each day, habit of answering the phone, position of MP during the day, mode of MP at night and the prevalence of inattention in adolescents. Adjusted OR were also calculated after adjusting for age, sex, urban/rural residence and whether living close to mobile base stations. The variables with $\mathrm{P}<0.1$ were included in logistic regression models used to assess the association. Assessment of the fit between the model and the data was gauged by the goodness-of-fit test and the log likelihood Chi-square test. Continuous variables, such as the years of MP usage, the minutes spent on calls daily and the time of entertainment, were split into tertiles. Choosing six or more "yes" of the inattention descriptions was defined inattention. Statistical significance was defined as $\mathrm{P}<0.05$ in this study. Categorical variables were summarized using the corresponding percentages, and continuous variables were generally summarized using descriptive statistics (mean \pm standard deviation (SD)). Statistical analysis was undertaken using SPSS version 19.0 (SPSS Inc., Chicago, IL, USA).

\section{Results}

\section{Descriptive information}

Out of 7720 currently enrolled students in the 4 middle schools, 294 (3.81\%) did not return the questionnaire. Out of the 7426 returned questionnaires, 324 (4.20\%) were incomplete. In total, 7102 (91.99\%) questionnaires completed in all sections (including the Demographic information, Information on $\mathrm{MP}$, and Inattention) were used in the analysis. The participants included 3613 males (50.87\%) and 3489 females (49.13\%). The mean age was $15.26 \pm 1.77$ years. A total of 5033 (70.87\%) of the participants resided in urban areas, and 2069 (29.13\%) were from rural areas.

Overall, 5668 (79.81\%) participants owned MP at the time of the survey and had been using a MP for a mean of $3.50 \pm 2.48$ years. Participants spent $57.36 \pm 71.96$ minutes on entertainment and $8.64 \pm 15.48$ minutes on making calls daily (Table 1). The details of the socio-demographic characteristics and MP usage are given in Table 1.

\section{Association between MP use and inattention}

There were 7294 (94.48\%) responses to the inattention questions. The overall prevalence of inattention was $69.79 \%$ out of the 7102 valid questionnaires in this study. After adjusted for age, sex, area of residence (urban/rural) and whether living close to mobile base stations, the prevalence of inattention was significantly associated with MP ownership (OR 2.92; 95\% CI 2.51-3.39) and time spent on entertainment daily (OR 1.87; 95\% CI 1.28-2.73). Additionally, there was a positive association between
Table 1 Descriptive data of socio-demographic characteristics and MP usage $(\mathrm{N}=7102)$

\begin{tabular}{|c|c|c|}
\hline Characteristic & \multicolumn{2}{|c|}{ Prevalence $\mathbf{n}(\%)$} \\
\hline \multicolumn{3}{|l|}{ Sex } \\
\hline Male & \multicolumn{2}{|l|}{$3613(50.87)$} \\
\hline Female & \multicolumn{2}{|l|}{$3489(49.13)$} \\
\hline \multicolumn{3}{|l|}{ Age } \\
\hline 12 & \multicolumn{2}{|l|}{$248(3.49)$} \\
\hline 13 & \multicolumn{2}{|l|}{$968(13.63)$} \\
\hline 14 & \multicolumn{2}{|l|}{$1340(18.87)$} \\
\hline 15 & \multicolumn{2}{|l|}{$1355(19.08)$} \\
\hline 16 & \multicolumn{2}{|l|}{$1119(15.76)$} \\
\hline 17 & \multicolumn{2}{|l|}{$906(12.76)$} \\
\hline 18 & \multicolumn{2}{|l|}{$669(9.42)$} \\
\hline 19 & \multicolumn{2}{|l|}{$194(2.73)$} \\
\hline 20 & \multicolumn{2}{|l|}{$19(0.27)$} \\
\hline \multicolumn{3}{|l|}{ Urban/Rural } \\
\hline Rural & \multicolumn{2}{|l|}{$2069(29.13)$} \\
\hline Urban & \multicolumn{2}{|l|}{$5033(70.87)$} \\
\hline \multicolumn{3}{|l|}{ MP Ownership } \\
\hline Own MP & \multicolumn{2}{|l|}{$5668(79.81)$} \\
\hline Don't own MP & \multicolumn{2}{|l|}{$1434(20.19)$} \\
\hline \multicolumn{3}{|c|}{ Whether close to mobile base stations } \\
\hline Close to mobile base stations & \multicolumn{2}{|l|}{$3920(55.20)$} \\
\hline Far away from mobile base stations & \multicolumn{2}{|l|}{$3182(44.80)$} \\
\hline Characteristic & Mean \pm SD & Min-Max \\
\hline Age & $15.26 \pm 1.77$ & $12-20$ \\
\hline MP use years & $3.50 \pm 2.48$ & $0-18$ \\
\hline Minutes on call (min/day) & $8.64 \pm 15.48$ & $0-180$ \\
\hline Time of entertainment (min/day) & $57.36 \pm 71.96$ & $0-480$ \\
\hline
\end{tabular}

inattention and the time spent on entertainment on MP (21-60 minutes per day spent on entertainment, OR 1.45, 95\% CI 1.06-1.97; >60 minutes per day spent on entertainment, OR 1.82, 95\% CI 1.28-2.59; Table 2). We analyzed the association between inattention and the position of MP during the day. The results showed significant differences. Compared to not carrying the MP (OR 1.00), hanging the MP in front of the chest (OR 0.44; 95\% CI 0.19-0.99) and putting the MP in a trouser pocket (OR 1.34; 95\% CI 1.10-1.62) were both significantly associated with inattention. Moreover, participants who powered off their MP at night showed significantly less inattention than those students who left their MP on at night (OR 0.75; 95\% CI 0.63-0.90; Table 3).

\section{Discussion}

This population-based cross-sectional study is one of the first studies to investigate the association between MP 
Table 2 Association between MP use time and inattention $(n=7102)$

\begin{tabular}{|c|c|c|c|c|}
\hline & n (\%) & $P^{\wedge}$ & OR $(95 \% \mathrm{Cl})$ & Adjusted OR $(95 \% \mathrm{Cl})^{\#}$ \\
\hline MP ownership & & 0.000 & & \\
\hline No (ref) & $541(38.21)$ & & 1.00 & 1.00 \\
\hline Yes & $4414(79.29)$ & & $5.73(5.05-6.50)$ & $2.92(2.51-3.39)^{* *}$ \\
\hline MP use years & & 0.095 & & \\
\hline $0-2$ years (ref) & $1568(76.34)$ & & 1.00 & 1.00 \\
\hline $3-4$ years & $1444(79.04)$ & & $1.16(0.99-1.35)$ & $1.07(0.88-1.31)$ \\
\hline$>4$ years & $1132(78.61)$ & & $1.14(0.97-1.34)$ & $1.05(0.85-1.30)$ \\
\hline Minutes on call & & 0.000 & & \\
\hline \multicolumn{5}{|l|}{$0-2$ years } \\
\hline 0-1 min/day (ref) & $344(81.32)$ & & 1.00 & 1.00 \\
\hline 1-6 min/day & $594(79.41)$ & & $0.87(0.64-1.18)$ & $1.15(0.82-1.60)$ \\
\hline$>6 \mathrm{~min} /$ day & $410(76.64)$ & & $0.76(0.55-1.06)$ & $1.16(0.81-1.65)$ \\
\hline \multicolumn{5}{|l|}{ 3-4 years } \\
\hline 0-1 min/day & $327(82.78)$ & & $1.05(0.73-1.51)$ & $1.06(0.72-1.57)$ \\
\hline 1-6 min/day & $495(82.14)$ & & $1.07(0.77-1.49)$ & $1.18(0.83-1.68)$ \\
\hline$>6 \mathrm{~min} /$ day & $398(80.08)$ & & $0.95(0.68-1.34)$ & $1.31(0.90-1.91)$ \\
\hline \multicolumn{5}{|l|}{$>4$ years } \\
\hline $0-1 \mathrm{~min} /$ day & $261(79.33)$ & & $0.86(0.60-1.25)$ & $0.92(0.62-1.37)$ \\
\hline 1-6 min/day & $378(83.44)$ & & $1.23(0.86-1.76)$ & $1.46(0.99-2.17)$ \\
\hline$>6 \mathrm{~min} /$ day & $338(78.42)$ & & $0.81(0.58-1.14)$ & $1.12(0.77-1.64)$ \\
\hline Time of entertainment & & 0.000 & & \\
\hline \multicolumn{5}{|l|}{$0-2$ years } \\
\hline 0-20 min/day (ref) & $548(79.42)$ & & 1.00 & 1.00 \\
\hline 21-60 min/day & 459 (79.69) & & $1.03(0.78-1.36)$ & $1.45(1.06-1.97)^{*}$ \\
\hline$>60 \mathrm{~min} /$ day & 317 (78.66) & & $0.98(0.72-1.32)$ & $1.82(1.28-2.59)^{* *}$ \\
\hline \multicolumn{5}{|l|}{ 3-4 years } \\
\hline 0-20 min/day & 410 (82.66) & & $1.22(0.90-1.64)$ & $1.11(0.80-1.53)$ \\
\hline 21-60 min/day & 440 (82.09) & & $1.18(0.88-1.58)$ & $1.33(0.97-1.83)$ \\
\hline$>60 \mathrm{~min} /$ day & $353(80.78)$ & & $1.19(0.87-1.62)$ & $1.80(1.27-2.56)^{* *}$ \\
\hline \multicolumn{5}{|l|}{$>4$ years } \\
\hline 0-20 min/day & 334 (76.78) & & $0.98(0.72-1.32)$ & $0.99(0.71-1.38)$ \\
\hline 21-60 min/day & 325 (82.70) & & $1.28(0.92-1.78)$ & 1.39 (0.97-1.98) \\
\hline$>60 \mathrm{~min} /$ day & $294(80.55)$ & & $1.11(0.80-1.53)$ & $1.87(1.28-2.73)^{*}$ \\
\hline
\end{tabular}

$\mathrm{P}^{\wedge}$ obtained through $x^{2}$ test.

"Adjusted for sex, age, Urban/Rural residence and whether living close to mobile base stations.

${ }^{*} \mathrm{P}<0.05$. ${ }^{* *} \mathrm{P}<0.001$.

OR: odds ratio, $95 \% \mathrm{Cl}$ : $95 \%$ confidence interval.

use and inattention in adolescents in China. Our results showed that the prevalence of inattention was considerable among middle school students. In this study, inattention in adolescents was significantly associated with MP ownership, the time spent on entertainment on the MP every day, the position of the MP during the day and the mode of the MP at night.

The prevalence of inattention in the present study was much higher than previous attention studies whether related to MP use or not $[28,29]$. Compared with the two previous studies investigating several symptoms including headache, fatigue and dizziness, our study focused only on inattention. This might have led the students to focus on this one symptom, resulting in the high prevalence of reported inattention. In contrast, the Mortazavi's study indicated that people in Iran are usually less familiar with the health effects of exposure to electromagnetic fields, therefore, the number of individuals reporting subjective 
Table 3 Association between MP use status and inattention $(n=7102)$

\begin{tabular}{|c|c|c|c|c|}
\hline & n (\%) & $P^{\wedge}$ & OR $(95 \% \mathrm{Cl})$ & Adjusted OR $(95 \% \mathrm{Cl})^{\#}$ \\
\hline Habit of answering the phone & & 0.798 & & \\
\hline Close to ear (ref) & $2616(80.20)$ & & 1.00 & 1.00 \\
\hline Hands-free & $783(80.72)$ & & $0.99(0.82-1.18)$ & $1.07(0.88-1.29)$ \\
\hline Use headphone & $567(81.23)$ & & $1.02(0.83-1.26)$ & $1.04(0.83-1.30)$ \\
\hline Position of MP during the day & & 0.000 & & \\
\hline Do not carry (ref) & $401(84.24)$ & & 1.00 & 1.00 \\
\hline Hang in front of chest & $12(44.44)$ & & $0.24(0.12-0.46)^{* *}$ & $0.44(0.19-0.99)^{*}$ \\
\hline In coat pockets & $239(77.60)$ & & $1.14(0.87-1.49)$ & $1.28(0.95-1.73)$ \\
\hline In trouser pockets & $1080(78.89)$ & & $0.98(0.83-1.15)$ & $1.34(1.10-1.62)^{*}$ \\
\hline In bags & $348(85.50)$ & & $1.14(0.88-1.47)$ & $1.04(0.78-1.37)$ \\
\hline Mode of MP at night & & 0.000 & & \\
\hline Power on and beside their heads (ref) & $922(52.12)$ & & 1.00 & 1.00 \\
\hline Power on and keep away from their heads & $466(42.02)$ & & $0.93(0.77-1.13)$ & $0.87(0.71-1.06)$ \\
\hline Power off & $612(32.74)$ & & $0.86(0.72-1.01)$ & $0.75(0.63-0.90)^{*}$ \\
\hline
\end{tabular}

$\mathrm{P}^{\wedge}$ obtained through $x^{2}$ test.

\#Adjusted for sex, age, Urban/Rural residence and whether living close to mobile base stations.

${ }^{*} \mathrm{P}<0.05$. ${ }^{* *} \mathrm{P}<0.001$.

OR: odds ratio, $95 \% \mathrm{Cl}$ : $95 \%$ confidence interval.

symptoms was considerably lower [29]. The higher prevalence of inattention in our study compared to other studies was also likely due to the higher prevalence of MP ownership $(79.82 \%)$ in our study than the Iran study (30\%).

Our results showed that the prevalence of inattention was significantly higher in MP-owning students compared to non-MP students. This finding concurs with Mortazavi's other studies which showed that there was a statistically significant relationship between the use of cell phones and attention disorder [30,31]. However, in their previous research, they did not find a significant association between MP use and self-reported symptoms [29]. We also demonstrated that the OR of inattention increased with the duration of time spent on entertainment on the MP per day. A longitudinal study also reported a similar time-dependent association between playing games on a mobile phone and attention disorder [10]. Attention deficit was associated with a weaker function and structure of prefrontal cortex circuits [32]. Moreover, Aalto et al. revealed an increase in regional cerebral blood flow more distantly in the prefrontal cortex while a mobile phone was in operation placed beside the subject's head [33]; this could be a reason for the increase in inattention. Because the time spent on making calls per day was not significantly associated with inattention, the effect of the MP on attentiveness might not be directly from the MP electromagnetic exposure but from the psychological impact. Inattention was found to be related to depression, anxiety, stress [34] and youth violence [35] in previous studies. A relationship between playing computer games [27,36], internet addiction $[37,38]$ and inattention has also been described. Moreover, superficial way to use internet or the contents of the games could also cause problems with concentrating. The time spent on games might also exacerbate ADHD symptoms, if not directly then through the loss of time spent on more developmentally challenging tasks [7]. In our present study, the strongest association between inattention and time spent on entertainment on the MP was among participants who spent more than 60 minutes per day playing on their MP. This is the first study so far to determine a time period which is correlated with inattention. Therefore, our results may provide a reference for further research into the relationship between MP use and inattention.

Hanging a MP in front of the chest and putting a MP into trouser pockets were both significantly associated with inattention. However, as only a small group of students (4.34\%) hang their MP in front of their chest, the association with inattention may not be generalizable. Our study also showed that putting MP into trouser pockets was likely to increase inattention in MP users. The side-pocket was the favored location for cell phones and students often send texts from inside a pocket. As the exposure increases rapidly in the near field, the safety limits may be exceeded when the phone makes contact with the base station and the penetration of the energy may increase with proximity if MP is in a pocket next to the carrier's body [39]. The poorer attention in those carrying the MP in a pocket might be due to students using MP while it was in the pocket. As our study found that adolescents who kept their MP turned off at night had significantly less inattention, 
we propose that parents should power off adolescents' MP while they sleep.

This large-scale cross-sectional study is the first to investigate the association between exposure to MP and inattention in Chinese adolescents. Because the questionnaire survey was proceeded during class time, there was a high response rate among the adolescents. Detailed MP usage and inattention were collected to fully explore the association. Furthermore, to exclude confounding factors, we adjusted the results for sex, age, urban/rural residence and whether living close to mobile base stations.

However, in this study, there may have been some exposure misclassification [40] due to the data being self-reported. Another limitation was that the crosssectional study design could not adequately reveal the causality of the factors [41]. On the other hand, as the protection of privacy for parents, schools only allowed us to collected the basic information of adolescents, such as sex, age, address, etc. Therefore, the confounding factors in this study were insufficient.

\section{Conclusions}

In general, the results in the present study indicated that MP ownership, the time spent on entertainment on the MP, the position of the MP during the day and the mode of the MP at night were all significantly associated with inattention in Chinese adolescents. We suggest that parents should set a maximum of 60 minutes daily playing by adolescents' on a MP and require them to turn it off when they sleep.

\section{Abbreviations \\ MP: Mobile phone; WHO: World Health Organization; ADHD: Attention deficit/Hyperactivity disorder; OR: Odds ratio; Cl: Confidence interval; SD: Standard deviation.}

\section{Competing interests}

The authors declare that they have no competing interests.

\section{Authors' contributions}

$F Z, Z Y$ and $L Z$ have made contributions to conception and design of the experiment. The experiment was performed by $\mathrm{FZ}, \mathrm{PG}, \mathrm{MH}, \mathrm{ML}, \mathrm{CW}, \mathrm{QZ}, \mathrm{ZZ}$, $Z Y$, and LZ. FZ and PG have made analysis and interpretation of data. Wrote the paper: LZ and FZ have drafted the manuscript. All authors contributed to the paper and approved the final version for publication.

\section{Acknowledgements}

This work was supported by the National Basic Research Program of China (National 973 Program; Grant No. 2011CB503700). We would like to thank Dr. Xiangyu Ma (Department of Epidemiology, Third Military Medical University) for discussion on questionnaire design and Dr. Xiaolu Zeng (Department of Epidemiology, Third Military Medical University), Dr. Dihui Ma (Department of Health Statistics, Third Military Medical University) for consultation on statistic analysis. We would also like to thank Yonghui Lu, Tao Zhang, Ling Mao, Gang Zhu for helping in distribution and collection of questionnaires and all of the participants and teachers for their participation.

\section{Author details}

'Department of Occupational Health, Key Laboratory of Medical Protection for Electromagnetic Radiation, Ministry of Education, Third Military Medical
University, NO. 30 Gaotanyan Street, Chongqing 400038, People's Republic of China. ${ }^{2}$ Suining Experimental High School, Sichuan 629000, People's Republic of China. ${ }^{3}$ Dongchan Middle School, Sichuan 629007, People's Republic of China.

Received: 2 July 2014 Accepted: 29 September 2014 Published: 1 October 2014

\section{References}

1. Jacobs K, Hudak S, McGiffert J: Computer-related posture and musculoskeletal discomfort in middle school students. Work 2009, 32:275-283

2. Jiang $X X$, Hardy LL, Ding D, Baur LA, Shi HJ: Recreational screen-time among Chinese adolescents: a cross-sectional study. J Epidemiol 2014, 24(5):397-403

3. Van Deventer E, van Rongen E, Saunders R: WHO research agenda for radiofrequency fields. Bioelectromagnetics 2011, 32:417-421.

4. China Internet Network Information Center: China Internet network development state statistic report. In China Internet Network Development State Statistic Report 33rd. Beijing: CINIC; 2014.

5. Van Egmond-Fröhlich AW, Weghuber D, De Zwaan M: Association of symptoms of attention-deficit/hyperactivity disorder with physical activity, media time, and food intake in children and adolescents. PLoS One 2012, 7(11):e49781.

6. Mazurek MO, Engelhardt CR: Video game use in boys with autism spectrum disorder, ADHD, or typical development. Pediatrics 2013, 132(2):260-266.

7. Weiss MD, Baer S, Allan BA, Saran K, Schibuk H: The screens culture: impact on ADHD. Atten Defic Hyperact Disord 2011, 3(4):327-334.

8. Divan HA, Divan HA, Obel C, Olsen J: Prenatal and postnatal exposure to cell phone use and behavioral problems in children. Epidemiology 2008, 19(4):523-529.

9. Van Rongen E, Roubos EW, Van Aernsbergen LM, Brussaard G, Havenaar J, Koops FB, Van Leeuwen FE, Leonhard HK, Van Rhoon GC, Swaen GM, Van de Weerdt RH, Zwamborn AP: Mobile phones and children: is precaution warranted? Bioelectromagnetics 2004, 25:142-144.

10. Byun YH, Ha M, Kwon HJ, Hong YC, Leem JH, Sakong J, Kim SY, Lee CG, Kang D, Choi HD, Kim N: Mobile phone use, blood lead levels, and attention deficit hyperactivity symptoms in children: a longitudinal study. PLoS One 2013, 8(3):e59742.

11. Zajdel R, Zajdel J, Zwolińska A, Smigielski J, Beling P, Cegliński T, Nowak D: The sound of a mobile phone ringing affects the complex reaction time of its owner. Arch Med Sci 2012, 8(5):892-898.

12. Carskadon MA: Sleep's effects on cognition and learning in adolescents. Prog Brain Res 2011, 190:137-143.

13. Milde-Busch A, Boneberger A, Heinrich S, Thomas S, Kühnlein A, Radon K Straube A, von Kries R: Higher prevalence of psychopathological symptoms in adolescents with headache: a population-based cross-sectional study. Headache 2010, 50(5):738-748

14. Sahin S, Ozdemir K, Unsal A, Temiz N: Evaluation of mobile phone addiction level and sleep quality in university students. Pak J Med Sci 2013, 29(4):913-918

15. Munezawa T, Kaneita Y, Osaki Y, Kanda H, Minowa M, Suzuki K, Higuchi S, Mori J, Yamamoto R, Ohida T: The association between use of mobile phones after lights out and sleep disturbances among Japanese adolescents: a nationwide cross-sectional survey. Sleep 2011, 34(8):1013-1020

16. Sudan M, Kheifets $L$, Arah O, Olsen J, Zeltzer L: Prenatal and postnatal cell phone exposures and headaches in children. Open Pediatr Med J 2012, 6:46-52.

17. Chu MK, Song HG, Kim C, Lee BC: Clinical features of headache associated with mobile phone use: a cross-sectional study in university students. BMC Neurol 2011, 11:115.

18. Childress AC, Berry SA: Pharmacotherapy of attention-deficit hyperactivity disorder in adolescents. Drugs 2012, 72(3):309-325.

19. Breslau J, Miller E, Joanie Chung WJ, Schweitzer JB: Childhood and adolescent onset psychiatric disorders, substance use, and failure to graduate high school on time. J Psychiatr Res 2011, 45(3):295-301.

20. Wallace D, Eltiti S, Ridgewell A, Garner K, Russo R, Sepulveda F, Walker S, Quinlan T, Dudley S, Maung S, Deeble R, Fox E: Cognitive and physiological responses in humans exposed to a TETRA base station 
signal in relation to perceived electromagnetic hypersensitivity. Bioelectromagnetics 2012, 33(1):23-39.

21. Schmid MR, Loughran SP, Regel SJ, Murbach M, Bratic Grunauer A, Rusterholz T, Bersagliere A, Kuster N, Achermann P: Sleep EEG alterations: effects of different pulse-modulated radio frequency electromagnetic fields. J Sleep Res 2012, 21(1):50-58.

22. Lee TM, Lam PK, Yee LT, Chan CC: The effect of the duration of exposure to the electromagnetic field emitted by mobile phones on human attention. Neuroreport 2003, 14(10):1361-1364.

23. Edelstyn $N$, Oldershaw $A$ : The acute effects of exposure to the electromagnetic field emitted by mobile phones on human attention. Neuroreport 2002, 13(1):119-121.

24. Lee TM, Ho SM, Tsang LY, Yang SH, Li LS, Chan CC, Yang SY: Effect on human attention of exposure to the electromagnetic field emitted by mobile phones. Neuroreport 2001, 12(4):729-731.

25. American Psychiatric Association: Diagnostic and Statistical Manual of Mental Disorders. 4th edition. Washington: APA; 2000.

26. Chaste P, Clement N, Botros HG, Guillaume JL, Konyukh M, Pagan C, Scheid I, Nygren G, Anckarsäter H, Rastam M, Ståhlberg O, Gillberg IC, Melke J, Delorme R, Leblond C, Toro R, Huguet G, Fauchereau F, Durand C, Boudarene L, Serrano E, Lemière N, Launay JM, Leboyer M, Jockers R, Gillberg C, Bourgeron T: Genetic variations of the melatonin pathway in patients with attention-deficit and hyperactivity disorders. J Pineal Res 2011, 51(4):394-399.

27. Tahiroglu AY, Celik GG, Avci A, Seydaoglu G, Uzel M, Altunbas H: Short- term effects of playing computer games on attention. $J$ Att Dis 2010, 13(6):668-676.

28. Costello EJ, Mustillo S, Erkanli A, Keeler G, Angold A: Prevalence and development of psychiatric disorders in childhood and adolescence. Arch Gen Psychiatry 2003, 60(8):837-844.

29. Mortazavi SM, Ahmadi J, Shariati M: Prevalence of subjective poor health symptoms associated with exposure to electromagnetic fields among university students. Bioelectromagnetics 2007, 28:326-330.

30. Mortazavi SM, Mahbudi A, Atefi M, Bagheri S, Bahaedini N, Besharati A: An old issue and a new look: electromagnetic hypersensitivity caused by radiations emitted by GSM mobile phones. Technol Health Care 2011, 19:435-443.

31. Mortazavi SM, Atefi M, Kholghi F: The pattern of mobile phone use and prevalence of self-reported symptoms in elementary and junior high school students in Shiraz. Iran Iran J Med Sci 2011, 36(2):96-103.

32. Arnsten AF: The emerging neurobiology of attention deficit hyperactvty disorder: the key role of the prefrontal association cortex. J Pediatr 2009, 154(5):I-S43.

33. Aalto S, Haarala C, Brück A, Sipilä H, Hämäläinen H, Rinne JO: Mobile phone affects cerebral blood flow in humans. J Cereb Blood Flow Metab 2006, 26(7):885-890.

34. Alexander SJ, Harrison AG: Cognitive responses to stress, depression, and anxiety and their relationship to ADHD symptoms in first year psychology students. J Atten Disord 2013, 17(1):29-37.

35. Massetti GM, Vivolo AM, Brookmeyer K, Degue S, Holland KM, Holt MK, Matjasko JL: Preventing youth violence perpetration among girls. J Womens Health 2011, 20(10):1415-1428.

36. Chan P, Rabinowitz T: A cross-sectional analysis of video games and attention deficit hyperactivity disorder symptoms in adolescents. Ann Gen Psychiatry 2006, 5:16.

37. Ozturk FO, Ekinci M, Ozturk O, Canan F: The relationship of affective temperament and emotional-behavioral difficulties to internet addiction in Turkish teenagers. ISRN Psychiatry 2013, 961734. doi: 10.1155/2013/961734. Print 2013.

38. Yen JY, Yen CF, Chen CS, Tang TC, Ko CH: The association between adult ADHD symptoms and internet addiction among college students: the gender difference. Cyberpsychol Behav 2009, 12(2):187-191.

39. Redmayne M, Smith A, Abramson M: Adolescent in-school cellphone habits: a census of rules, survey of their effectiveness, and fertility implications. Reprod Toxicol 2011, 32(3):354-359.

40. Schuz J, Johansen C: A comparison of self-reported cellular telephone use with subscriber data: agreement between the two methods and implications for risk estimation. Bioelectromagnetics 2007, 28:130-136.
41. Zhi S, Guoying D, Jipeng L, Yangyang L, Yongxing Z, Zhao Q: Correlational analysis of neck/shoulder pain and low back pain with the use of digital products, physical activity and psychological status among adolescents in Shanghai. PloS One 2013, 8(10):e78109.

doi:10.1186/1471-2458-14-1022

Cite this article as: Zheng et al:: Association between mobile phone use and inattention in 7102 Chinese adolescents: a population-based crosssectional study. BMC Public Health 2014 14:1022.

\section{Submit your next manuscript to BioMed Central and take full advantage of:}

- Convenient online submission

- Thorough peer review

- No space constraints or color figure charges

- Immediate publication on acceptance

- Inclusion in PubMed, CAS, Scopus and Google Scholar

- Research which is freely available for redistribution

Submit your manuscript at www.biomedcentral.com/submit 